Kohl: a Journal for Body and Gender Research

Vol. 2, No. 2 (Winter 2016)

\title{
How do Sex Workers Perceive their Working Identity? Case Studies in Egypt
}

Sara Abed

\begin{abstract}
:
This study looks at Egypt's sex workers' perceptions of their working identity. It examines the different experiences and attitudes of sex workers by exploring the main features and dominant frames in the literature, and how it could be of relevance in the case of Egypt. Through conducting interviews with sex workers and other stakeholders, I argue that sex workers tend to perceive themselves as workers who should enjoy labour rights, except for those who consider religious guilt and shame as a barrier in being visible to the public. The decriminalising of sex work diminishes state control and discrimination over the lives of sex workers in Egypt. My findings demonstrate that there is a relationship between state policies to discipline sex workers and the control of women's body.
\end{abstract}


As you roam the streets of Greater Cairo, outdoor sex work is quite noticeable, along with the presence of indoor and escort services. However, due to their criminalisation and marginalisation, sex workers lack access to healthcare, as well as to social and legal protection.

Sex work was legal in Egypt until 1951. A 1905 regulation used to organise the legal, medical, and social side of the profession. Sex workers carried licenses and were subjected to regular medical inspection to control/regulate STIs. Later on, Law 68 of 1951 was amended with a slight modification under Law 10 of 1961 , whereby the state outlawed sex work and considered it a crime. Due to its criminalisation, there is no precise/reliable demographic information on the number of Egypt-based sex workers or the type of sex work they engage in (Kabbash, Abdul-Rahman, Shehata, and Omar 2012: 23-25). Nevertheless, this research is not concerned with numbers, as the nature of the project is qualitative. I instead try to open a venue to discuss and analyse sex workers' attitudes, experiences, and concerns. I also draw on the current global literature to assess the extent to which it could be of relevance in Egypt's case.

Literature on sex workers in Egypt is rare and limited to the historical context of sex work and/or STI/HIV, and sex workers' perception of their working identity is scarce. Many studies from the current existing literature argue that sex work should be regarded as work, and it should be decriminalised rather than legalised to guarantee their social and legal rights (Gangoli 1998: 505; McClintock 1992: 89-90), as well as, preventing state control. I would like to add to the existing literature, delve deeper into the issue of female sex workers' perception, attitudes and experiences, and understand sex workers' rights from their own standpoint. For the purpose of my research, sex work includes, but is not limited to, prostitution, escorting, street hustling, stripping, and performing sex for videos and webcams (Grant 2014).

Sex workers' in Egypt tend to perceive that they should enjoy labour rights like any other profession does, according to my qualitative research findings. Decriminalising their work might guarantee such protection, where the state's control over their bodies, along with sex work stigma, would diminish. Although some could give up on their visibility in order to avoid religious guilt and shame, they still believe that other sex workers should claim their rights. I reflect upon the state's perception of "legal bodies" and sex work, in comparison to sex workers' own perception of their bodies and profession. In this light, sex work is a demonstration of one form of disciplining female bodies by criminalising their profession.

Yet, some scholarship accounts for the probability of the interests of politicians, state managers, and business owners to overshadow the concerns of sex-workers, whether sex work is criminalised, decriminalised, or legalised. Bernstein (2007: 165) deems "a simplification of political dynamics, including a failure to consider the multiple motives of political actors" at fault of such optimistic view on decriminalisation.

Since sexuality was shown to be a significant component of authority/governance, Foucault argues that authorities use disciplinary methods to command individual bodies through his bio political theory, resulting in state racism, and - I would add - sexism. Sexuality involves individual conducts through 
procreation/reproduction that have an effect on the collective body of the populace. In this regard, the regulation of sexuality was viewed as an essential move to contrast the dispersal of racial deterioration. The argument here is that the rise of state-racism has huge influence on the social structure of sex workers as pathological danger. This is shown in regulationism policies that serve to discipline them, and/or abolitionism policies that call for social purity and moral reinforcement (Biancani 2012: 38-40). State racism is also reflected in the practices within sex work. In Dubai, lighter-skinned and higher-paid sex workers encounter their potential clients in semi-private spaces such as the internet or their private connections, whereas darker-skinned and less-paid sex workers encounter theirs on the streets. Mahdavi (2010: 946) explains that sex work in Dubai is hierarchal, in which the demand is set in accordance to "perceived race" (linked to migrant origin's nation). This unintentional "racialisation" is due to, and leads to, the "spatialisation" of sex workers themselves. Thereby, racial power dynamics do not remain confined in the realm of the governmental oversight and protection of national values, but rather transcend it to become an integral part of the dynamics of the profession.

Accordingly, Biancani (2012: 40,48) argues that by examining Foucault's theory, state policies in disciplining sex workers can be perceived as a source of power, rooted in supervision, command, and the exclusion of female individual bodies. This was represented in the supervisory methods of power by establishing state-licensed brothels in Egypt and elsewhere. Sex workers were confined, examined/inspected, and cured for the purpose of commanding the aggregate biological consequences that disturbed the "collective body of population." They provide sexual relief for men who buy sex, thereby protecting the "good" women from rape in the double-standard imagination (Sultana 2015: 780). In this regard, the risk presented to public health was the spread of venereal diseases/illnesses from promiscuous/immoral sex.

Biancani (2012: 279,287) asserts that despite some prostitutes being subjugated by pimps, Egyptian women were able to make autonomous choices, for instance, by avoiding registration by working underground, or utilising the legal system to litigate their lover-pimps and independently manage/control earnings. This concludes that sex work is not about female subjection/subordination and/or a structure of gendered and class exploitation; instead, it could provide an opportunity to be economically independent and support their dependents. Correspondingly, I aim to examine the perceptions and attitudes of sex workers towards state policies in the context of discipline and control of the individual's body.

Biancani (2012: 284-285) also shows that in the restoration of cultural authenticity, oriental and Islamic righteous customs were put in place to prevent the destructive western-imported ideas. These were arguments and segments that backed up the abolitionism approach and were associated with culture and religion, even by secular-oriented middle-class-Effendiyya. A similar approach was adopted in the 70s and 80s, whereby the police in African countries - like Zimbabwe, Gabon, Zambia, Tanzania, Mozambique and Burkina-Faso - assaulted autonomous working-women under the umbrella of cleaning metropolises from prostitution (McClintock 1992: 82). 
On the other hand, White (as cited in Gilfoyle 1999: 124-125) argued that prostitution in Nairobi was not verification of social pathology, moral decay, or male domination. It was a means to form families in the city or support relatives in the village. It was a profession that supports indebted cash-crop producers or famine sufferers. Sex work during Nairobi's colonial times sustained transitional families. The nonexistence of pimps enabled them to command their earnings and clients. Hitherto, she argues that male domination, particularly pimps, arrived subsequently to state criminalisation.

Marxists and feminists are concerned with whether sex work provides an opportunity to progress lives of unskilled/vulnerable working-class women. Feminists continue to differ regarding sex work (Biancani 2012: 30-31,139). For instance, Grant (2014) claims that it is misleading to regard all types of selling sex a consequence of the same phenomenon (violence, deviance, or desperation). Grant argues that anti-sex workers rescuing efforts to restore, discipline, and make them "good women" maintains cheap labour and schemes for the saviours to manage. Similarly, Emma Goldman (an anarchist feminist) and Selma James (a socialist feminist activist) (as cited in Grant 2014) argue that those campaigns or jobs do little for sex workers; they actually generate more political occupations, such as inspectors and investigators.

Grant (2014) further argues that sex work should not be regarded as a profession in case it is "good" work and that one enjoys doing it. It is nonsense to condition sex workers' rights on how they love or feel empowered by their profession, as it is a reluctant perception. In this regard, Pollitt (2014) claims that one should treat those women as free agents, possibly even empowered, in cases where they earn good money. However, she points out that feminists should not call for the normalisation of sex work because they acknowledge that sex is something that women "have" and men "get," which is related to rape culture. She argues that we should examine sex work from the scope of equality not just liberty. Additionally, McClintock (1992: 95) made a very crucial distinction against the traditional narrative that purports that prostitutes sell themselves. Instead, she states that they exchange/trade a service for money and negotiate terms and conditions like other professions. She claims that one should educate men to respect sex worker, hence respect all women.

Ghosh (2006: 1289) and Gangoli (1998: 504-505) argue that the silent revolution in India, led by the Sonagachi project, empowered sex workers through addressing sex as work. They assert that erasing the picture of sex workers as a diseased body and treating them as workers was an essential aspect. In this regard, their calls for equal rights like any other work necessitates the removal of moral/social stigma connected to their job (Nag 2003: 4209-4210; 2005: 5151-5152). Correspondingly, Margo St. James, an ex-sex worker, founded Coyote NPO for addressing sex work as any other form of work. Ironically, assumption of lack of agency and victimhood makes sex workers "deserving" of aid in forms of NGO health assistance, whereas those who enter the field by choice are painted as predatory and undeserving the aid. The Euro-American anti-trafficking feminist benign, yet intensely defective and naive movements to rescue, "enlighten" or "civilise" the stray or "fallen" woman are underpinned by this sort of reasoning (Mahdavi 2010: 949). 
McClintock (1992: 77, 82) asserts that the patriarchal societies fear women's capabilities to have the means to obtain income because marriage, male monopoly of resources, and means of production are endangered. McClintock (1992: 72-73, 77) argues that sex workers trials are a form of violence. While the notion of fine aims to restore economic trade undermined by sex workers into male exchange, she further clarifies the problematic notions that sex workers and wives are believed "unrapeable." She argues that it does not mean that men have command over sex workers because they have access to their services. Equally, Gangoli (1998: 504) also addressed a very crucial point on how anti-prostitution laws could raise the notion of inviting an interrogation of all female bodies. This means that anti-prostitution laws defining her as a prostitute, her body will be perceived as accessible/available to all. This demonstrates that antiprostitution laws control all women's bodies.

Some oppose the idea of treating prostitution (one form of sex work) as a profession, such as Farley (1994: 14) and Holder (1994: 24 as cited in Holder, Goodson and Farley), arguing that it is a human rights issue that is to be looked at from the scope of violence against women. They argue that women are forced into it due to economic and physical reasons. It is no deviation from popular discourse on sex work that bases itself upon the victim/agent dichotomy, in which sex workers are either victims of social and economic situations or [agents] in control of [their] life (Sultana 2015: 778). Several feminists argue that prostitution is a degrading and inhuman profession (Liberto 2009: 138-139). For instance, Pateman (1992: 62) argues that men in a patriarchal society are confirmed overtly to be the women's sexual master due to the fact that women bodies are sold as commodities in the capitalist markets. Nonetheless, Goodson (1994: 24-25 as cited in Holder, Goodson and Farley) criticises Farley's stance and argues that abolitionists do not respect women's right by denying her the right to choose her profession; instead, a huge public hostility/aggression against sex workers was made obvious via scapegoating them. For this reason, I intend to look at Egyptian sex workers' self-perception of their profession, which raises the question: what is the impact of the criminalisation of sex work on sex workers' bodies? By doing so, I am not simply focusing on the argument that sex work should be treated as work. In fact, I am addressing their perception of the criminalisation of their profession, and how it impacts their lives in a particular manner, such as being treated as "unrapeable" and/or outcasts.

Concerning the ethics and risk assessment precautions of my research, an informal verbal consent by all interviewed sex workers was taken before proceeding with the interviews due to the illiteracy of some of my interviewees. I read an information and consent sheet to make the participants aware of the study objectives, nature, terms, and conditions of the research. I provided them with formal consent sheets upon request. Moreover, all participants are anonymous for their own safety, including the name of the NGO.

It is crucial to mention that each of them was given a second opportunity to consent or withdraw their participation at any time during the interview. Also, they had the right not to answer any or some of my interview questions. I made it clear that their participation is completely voluntarily and does not in any way impact their status with the NGO that assisted me in interviewing them. 
Most of my interviewees requested not to be given fictional names for safety/security reasons. Hence, I had to represent them in numbers for consistency. It is vital to pinpoint that the tight timeframe (two months) of my master's thesis, along with the limited access to sex workers mostly influenced my decision to accept such terms rather than searching for sex workers who would approve to have fictional names. Additionally, the risk assessment procedure - at $U C L$ - required me to recruit my research participants via an NGO, which was another limitation as I was restricted to only those who seek services at the NGO.

\section{Description of Sample: Former and Current Work, Price Range, and Obstacles ${ }^{1}$}

This study is based on semi-structured interviews that I conducted in Greater Cairo, Egypt, from June 15 to August 72014 with 20 female interviewees. Sex work is the only source of income for 15 participants, and most of them, except for two, are the main breadwinners of their families. One participant is a freelance tailor, and the second one occasionally works in restaurants. Another participant who used to do other work alongside sex work is no longer a sex worker as her partner was against it. She is a creative/copywriter and used to be a teacher, a literary researcher, and an editor in chief. Three participants gave up this profession because they found other work opportunities of their interest; in addition, the husband of one of them imposed this as pre-condition for getting married. Some respondents emphasised that their work outside the sex industry is more exploitative, inflexible, and without any hopes for financial stability.

17 of the participants do indoors sex work. Three of them sometimes find work through pimps and two are sex workers and pimps. The others work independently via means such as nightclubs and escort agencies. One of the interviewees rents a flat as her workplace. In the research sample, three sex workers do indoors and outdoors sex work. Those who do it outdoors claim that it puts their safety at risk and are more exposed to police or strangers' sexual exploitation, violence, kidnapping, or insults. For instance, one participant was accosted a stranger who threatened to take her veil off because of her profession. She claims that everyone should have the right to practice their religious and social believes regardless of their profession. Hence, she felt offended as he invaded her rights and private space simply because of the nature of her work. This demonstrates how sex work is stigmatised, with the state paving the way for the society to have control over women and their bodies, and using sex workers as scapegoats. Nevertheless, this does not negate the fact that indoors' sex workers get exposed as well.

\footnotetext{
${ }^{1}$ For the purpose of this research, I utilised thematic coding analysis to aid me in interpreting patterns (Guest, Bunce and Johnson 2006: 77-78). I started by acquainting myself with the findings via transcription and a technique of continual reading to produce preliminary codes. These codes should assist me in identifying similarities among different aspects of the manuscript. I then sought relationships between similar attitudes/behaviours among sex workers in dealing or responding to a certain issue related to their job. Later on, I created initial codes and classified them to fit them within themes, tailoring the code if required, to generate a thematic map of my findings. Finally, I constructed thematic networks that involved integrating and interpreting the patterns in my study to test my hypothesis (Robinson 2011: 475-476).
} 
Prices range from 50 Egyptian pounds to 2000 Egyptian pounds, or 250 dollar per hour. It depends on multiple factors such as health condition (one of them had breast cancer, which affected the price of her service), type of service provided, working hours, and the client social class. Apart from cash payment, some may accept payment via gifts, such as perfumes. Those who partner with one client for an extended period of time usually demand that their client pays for their expenses, which may include the expenses of their children, apartment rent, and travel. Four of the participants who used drugs would accept such substances as means of payment. Clients vary from middle to upper class Egyptians, Saudis, Yemenis, Americans, and Europeans. Some have clients from the police, military, and judiciary sectors. One of them revealed that she just deals with "billionaires," such as bankers, pilots, and businessmen. Another respondent mentioned that she only deals with clients who are in top positions in their countries, specifically clients from the Gulf. Some of them described their clients as "classy gentlemen" from Egypt.

Most respondents mentioned incidents of harassment, rape, and violence by clients, police and others. In addition, sex workers stigma is another problem they face. Other problems vary from non-paying clients, robbery, to being forced to provide the service to multiple people at a time.

\section{"Unrapeable" Bodies}

When ordinary people know that you are a sex worker, they treat you as a bad person. Some people may not even talk to you anymore, and they may even talk about you... Why do people not agree that this is like any other profession? This profession exists, and society cannot get rid of it.

17 respondents claim that they provide a service like many other professions, and that they should not be perceived as being shameful or having a diseased body. Most of their responses raise the issue that women in general are blamed for any harm against them; this puts sex workers in a difficult position, as they are at the risk of public shaming. They believe that they should be accepted by society without any concern or any false stereotypes against them. An interviewee explains the origin of such societal judgement:

It is a patriarchal society. They will always say he is the man; he can do whatever pleases him. But girls have to worry about their reputation and people's perception of her all the time. This is unfair.

All of the respondents confirmed that they are in constant exposure to being treated in a degrading manner. This varies from insulting them to harassment or rape. The fact that they provide a sex service does not give the clients/people the right to control their bodies. It is their body's right to decide when, how, and who will get such service. It was clearly elaborated that this view is by no means a female sex worker problem; instead, it is a women problem, where they are blamed by society in such cases. According to such narrative, sex workers' bodies are viewed as unrapeable. One way of dealing with such phenomena is to educate people to respect sex work. 
I was raped several times by my clients and their friends under the threat of weapons. The working conditions of such work pave the way for such acts. I am suffering psychologically because of what I have been through. Several of my clients and their friends illegally imprisoned me for a week and used to rape me on a daily basis. Those clients were ordinary people or police officers... Some clients may beat you up and force you to do certain positions. They want to show that they are masculine and strong.

The notion that sex workers are perceived as unrapeable makes them suffer in different ways:

Some clients' forced to do certain positions or they were sadistic. If you disagree, they would tell you: I pay you to do whatever I ask for. It is not because you paid for a service that you can do whatever you want. I am lucky because I was aware of what rights I should have. So I started applying those rights informally with my clients.

In addressing power dynamics, it was obvious in my findings that some police officers abused their power to dominate sex workers by torture, or extorted free service. If they did not comply, the officers threatened to file cases against them:

One of my colleagues in my masters' programme is a cop, I used to ask for his help to obtain my tuition fees' receipts in a speedy manner to receive funds from the NGO to support me in completing my studies. When he knew that I was a sex worker, he asked me to provide him with sex services without anything in return. I did not want to provide him with such services. He disgusted me, as he was abusing his position. I had to provide him with such services to escape any harm. In any profession, it is a mutual agreement between two working partners. People provide services in exchange of something. But according to him, he was not obliged to keep his end of the bargain.

The interviewees do not doubt that the chances of getting raped are extremely high, not so much due to the profession itself, but rather to the patriarchal perception of it, and the notion that women who sell sex are unreapable:

I was never arrested. But based on the stories I heard from other colleagues in the profession, I am sure I will be sexually exploited. If I refuse to sleep with him, he will tell me "you are a whore anyway, how come you do not want to do it with me?"

Some respondents indicated that state discrimination is directed towards women in general. The state discriminatory policies place women in a situation where they could be sexually exploited, treated as sex objects, and be asked for sex bribes. In addition, they should not claim their rights because of shame, and could be blamed for any act: 
I was finishing my divorce papers in the police station, and one of them wanted to sleep with me to fasten the divorce paper work procedure. This is his work, and I should get this service without

anything in return. Generally, whenever I get harassed and make a case at the police station, they let go of the perpetrator... The government and the society created such stigma on women to control their choices. I read Qasim Amin's book, which made me realise that I was an object to my ex-husband. He used to beat me up to obey his orders. This is why I asked for a divorce. It is my body's right, and no one should dictate to me what not to do.

Social stigma and state discrimination on sex work continuously allow police agents to abuse their power without being held accountable. That being so, it grounds the notion of unrapeable bodies by undermining sex workers' agency in the public eye.

\section{Illegal/Unlawful Bodies}

Sex workers who perceive themselves as workers are anxious of their current condition. They are tired of the sex work stigma associated with their profession. This stigma has both legal and religious roots; their bodies are illegal in regards to the common law, and unlawful in regards to religion. Some of them assert that the stigma is one of the major problems they encounter in their job. This is due to the fact that they cannot have a "normal" life and be treated like other citizens, as they are always viewed as "odd" and "bad." They believe that if society's perceptions of sex work changed, they would easily be able to reclaim their rights. If they were not labeled as "prostitutes" as a job title, it would positively reflect on their integration in the society. Some of their concerns about how such stigma affects their personal lives vary. For instance, the boyfriend of one of them was about to break-up with her because of her profession. Others claim that they cannot get married for the same reason as they are viewed as haram (sinful). One of the participants asserts that we should remove the stigma associated with paid sex service, as it is no different from unpaid sex.

Four sex workers, two of whom retired, expressed their views on how there is a relation between guilt and the kind of work they do.

I feel ashamed. I want to do another job. I hate my job because of people's treatment. I am afraid to die while I am still doing this job. But I still believe that I should be protected and the police do not have the right to arrest me whenever they want. I want to change my job so I can look into people's eyes. I will kill my daughter if she takes a similar path. I do not want her to be raped, imprisoned, or killed by clients.

Even though four of the sex workers interviewed may believe that their profession is sinful, they still agree that they should have some sort of guaranteed healthcare and human rights that are distinct from their right not to be tortured or harassed. 
One of the respondents claims that her own perception of her former profession as a sex worker, along with the peer pressure of her friends, made her realise how degrading and sinful her job is:

At first, I used to invent excuses to continue as a sex worker. My friends advised me to quit my job because it is bad. After a while, I realised that I was cheap, and then later I started considering the religious aspect of my job. My friends found me another job to do. Now I can look at people's eyes. It should stay illegal so not many people get into it.

This case may shed some light on the role of peer pressure associated with sex work stigma. Another respondent asserts that she is always confused between her religious beliefs and other sex workers' rights to choose their job. Nonetheless, she made it clear that it is a personal choice to view her profession from a religious perspective and that other sex workers should enjoy their full rights, as long as their beliefs are not contradictory as hers are.

Sex work stigma makes their lives full of fear and worry, as they are always apprehensive about being followed by someone who may cause them harm. The lack of protection prevents them from filing charges in cases of burglary and all forms of violence against them:

You cannot have an official relationship because you are haram (sinful). When I was pregnant, his mother hired thugs to hit me with a car. I lost my baby. He is a judge, and he can get rid of me easily since I am not protected because of my profession... I had to have an abortion a couple of times because not all clients agree to wear condoms. It decreased my chances to have a baby. I also had Chlamydia (STI), and I was treated by the NGO. I told him about it so he could get treatment as well.

Criminalisation underpins the notion that sex workers' should neither have control over their bodies and their well-being, nor perceive themselves as workers. This undermines their position to express their emotional standpoint concerning their working identity.

State discrimination towards sex workers, as well as police violence and exploitation, are one of the vital themes that arose from the data. Those practices illustrate the power dynamics and discriminatory laws that serve to discipline sex workers' bodies. Many respondents stated that they experienced police arrest. Charges against sex workers vary from falsification, prostitution, or inciting immoral behavior, and most of the respondents indicated that they were threatened and harassed by police officers, which involved coercion and rape.

In other incidents, the police fabricated cases to fill the empty slots in the prostitution folder. They would arrest some girls in the streets or coffee shops, even when they are not working, merely because they had previous similar cases against them. The officers may ask for sex bribes or take their money in exchange of setting them free. One sex worker used the name of her ex-husband who is a police to get away from such situations. 
This briefly portrays the state's practice of gender discrimination, regardless of the nature of their job. According to the NGO's staff, the police violates the legal procedures: the Egyptian laws dictate that they should seek permission for the arrest, and they should arrest them while in the act of sleeping with a client. However, in most cases, women are arrested on the streets in accordance with their previous cases, class, or physical appearance. One can argue that the state aggression is a major factor in the deficiency of sex workers' rights. In this regard, if the state changed its policies towards sex workers and treated them as workers rather than criminals, social stigma would diminish. Accordingly, it would pave the way for sex workers to achieve their rights, and report harassment incidents:

I am in a deep fear all the time of getting arrested or harmed by anyone. I will not be able to claim or ask for my right because I am always viewed as a criminal. The decriminalising of sex work will give me some protection. At least I will not be scared to file a case against the perpetrator.

Disciplining sex workers is another approach used by the state in Egypt. Almost all of the respondents are totally against such approach, and view it as a discriminatory act. According to their responses, the state's approach to disciplining sex workers varies from sending them to public entities, to insulting and torturing them:

A policeman slapped me while he was checking my identity outside my workplace (nightclub). He kept on asking me whether or not I was virgin.

Public inspections in the streets constitute an additional approach refused by sex workers, as they consider it to be a violation of their rights:

I should not be inspected without my consent in the streets. I should not be penalised when they find condoms in my bag. According to the current laws, no one has the right to do so. In practice, condoms are used against me.

However, the laws related to sex work are discriminatory by themselves, and enable the state and its entities to perpetuate their discriminatory acts with impunity:

It is a discriminatory law in the first place. If you get caught while in the act of having sex, the man is considered a witness against me. Even when they set unfair laws, they make sure that they are harsher on women. Where is the equality? Why are women portrayed as seductive and devilish creatures? The laws are full of stereotypes and discrimination.

The Egyptian law regards the male sex partner/client as a witness, even though he is a consenting party who sought sex services. Even under criminalising laws, the unjust treatment of sex workers highlights the patriarchal dimensions rooted in the state policies and practices. 
The state agents' attitudes towards sex workers displays how criminalisation has been utilised as a tool to control, discipline, and exploit women's bodies. The state policies perceive sex work beyond the notion of crime, as these bodies are conceived to be sinful, and thus unrapeable. The framework of "legality" reinforces the discourse that sex work is not a profession, as it strengthens the idea of "illegal beings" (sex workers are not desired to be among us). Additionally, the state agents' misuse of power - by exploiting those same bodies to serve their own interests - reflects on their investment in maintaining the power dynamics in favor of their conventional gender identity.

To escape the illegal/unlawful boundaries of their profession, some sex workers recur to informal contracts and commonly approved ways to increase their safety. Marriage with all its different forms is used by some of them to prevent arrest:

I usually write an Ourfi paper (marriage paper without formalised ceremony), so in case of arrest I can get away with it. I have no other options.

One of the respondents did a marriage deal with her pimp: in case of arrest, he would declare that he forced her into this profession, even though she was not forced into it. In doing so, she believes she can get away with it. She argues that he will not be harmed since men, unlike women, can easily escape the law in such cases.

I perceive it as a profession, but my brother does not. He denies that it is a form of sex work due to the fact that I do it in the form of marriage. I believe that marriage is an excuse to make my client and brother feel that they are not doing something haram (sinful).

The institution of marriage is one of the patterns of "legality" where Egyptian sex workers are concerned. Not only does it diminish the risk of arrest, but it is used as a pretext to undermine the guilt associated with religious shame by family members or clients. However, it also contributes to the control over sex workers' position towards their work identity. Due to the nature of sex work, the interplay of the concept of legality and religious guilt influences sex workers' self-perception of their work identity - they become 'illegal bodies." Such hegemonic culture gives the upper hand to the state and society members to decide on the criteria of how a legal body should look like or act.

\section{Need for Unionisation: Labour Rights}

Sex workers somewhat manage to maneuver the constraints built by the religious and legal institutions around them, in an attempt to protect their bodies from being treated as disposable. The sex workers interviewed believe they should be able to access sexual health services, enjoy their sexual rights, and unionise. 
Most respondents assert that their health is very crucial to them. They regularly ask the NGO to do regular check-ups. Some of them follow up with their own doctors. Only two do not undergo regular check-ups; one of them claims that she mistrusts doctors, and described them as "money-generators." Some of them would not provide sex service without a condom, while the rest may not use it upon the client's refusal.

Most of them fear the result of the check-ups, but do not worry that it may be used for any other purpose. According to all the sex workers respondents and the Manager of the National AIDS Programme, medical check-ups are done with their consent and the results are kept confidential. Since their profession is not legalised, check-ups are not conducted in the form of medical inspection. Only two respondents were worried that the result may stigmatise them socially. It is important to point out that the NGO provides awareness sessions to the outreached sex workers with regard to health and safer sex practices. Due to those sessions, some sex workers are outspoken on these issues and take precautionary measures to protect themselves, such as using condoms or restricting their clients to certain trusted people:

I always check my clients' organs to make sure they are free from herpes. I use condoms, and I restrict my clients to people who I am sure take care of themselves. Whenever I have any inflammation, I take a break until I recover. I care so much about my health, and others do too.

I use tops (condoms) and I limit my clients to a couple of people. I always do regular check-ups with the NGO.

It is worth noting that as long as sex work is criminalised, health issues remain a challenge. For instance, sex workers cannot insist on condom usage because they have no rights to claim.

I perceive myself as a worker. I should have the right to pensions and healthcare, and be able to set my conditions when I provide any sex service. I always feel that the entire world is against me... What I do is work... Why are we treated like something dirty and useless? We should be accepted and we should have a trade union.

Sex workers' responses show a great knowledge of what their rights and duties should, and how to practice them under what they view as "unlawful laws." In this regard, they associate decriminalising sex work with social and legal protection, and some of them believe/identify that such rights will eventually reduce harm and sex work stigma. Even though most of the respondents do not recognise the difference between legalisation and decriminalisation and may use both terms interchangeably, they make a viable differentiation between having a license and having labour rights. Some of them believe that having a work license or being monitored/inspected contribute in augmenting the stigma. This demonstrates that there is a relation established between being a sex worker and having labour rights, as well as between the legalisation of the profession and sex work stigma. Some sex workers believe that the right to form a trade union could support them, but they also understand that registering with a union should not be a prerequisite to attaining their labour rights. 
I do not view it as a profession because I had a religious upbringing. [...] For those who regard it as work, they should have labour rights. But we should change the term prostitute. It has negative connotations. If we will have a trade union, it should be under labour union or it should be called a different name.

Sex workers in Egypt look for other ways to impose their terms and conditions. They assert that they need to find alternatives to make their work safer and mitigate power dynamics. In many incidents, sex workers in Egypt have adopted some practices to overcome the unavailability of labour rights. Nonetheless, considering the lack of protection, they still face several problems that could be life threatening, and/or suffer from health issues. While some of them managed to secure their labour rights informally with their clients or take some precautionary measures in order not to get arrested, others could not file a case against a client for not paying for the service due to the lack of supportive legal coverage.

Since I provide a service, I should have legal protection. I started practicing my rights informally. For example, I always do contracts before providing any sex service. I lost many clients because they refused to wear condoms. We should have a trade union. Our current trade union is the NGO. What I care the most is a real body to represent us. There are plenty of trade unions in Egypt, but do they really represent their workers?

Almost all the respondents agree that if they ever decided to unionise, the state will use the same disciplinary approach to control them and prevent them from achieving their objectives:

It is really hard to achieve such rights. The state will always counter our demands with religious slogans, while some of them are our clients. It is halal (justifiable) to them and haram (sinful) to us. They are hypocrites and use religion as a pretext to control and prohibit whatever they want.

Sex workers who demand labour rights are mostly skeptical about their practicability in the near future, especially if the status quo remains in place. Despite the expressed need to unionise, sex work stigma associated with their job is reinforced by the governmental exploitation of existent and non-existent laws. This renders the creation of a union unlikely unless a radical change in the socio-legal Egyptian systems directly addresses institutionalised discrimination, disciplining, and the policing of sex workers' bodies.

\section{Conclusion}

Sex workers in Egypt believe that the bad treatment they get is a result of how society perceives the type of work they do. In addition, the misperceptions associated with their profession, such as having a diseased body, are merely rooted in the patriarchy that limits women's choices. This amply results in constant fear to ruin their own and/or any of their family members' reputation. Accordingly, they cannot claim any of their rights publicly in order not to be shamed or blamed by anyone once their profession is uncovered. 
Moreover, their bodily rights are breached due to the mistaken notion that their bodies are unrapeable. Decriminalising sex work by putting it under commercial law will contribute in sex workers' plight to claim their rights, such as reporting incidents of sexual assaults. They may also be able to do medical check-ups under their consent without the fear of being stigmatised.

Some sex workers practice their rights informally with their clients. They set their terms and conditions, such as working hours, type of sex service, price range, and condom use. Some of them may even issue a marriage paper (without a formalised ceremony) to further protect them in case of arrest. The NGO they refer to provides sex workers with healthcare and legal services. Nonetheless, the lack of protection puts them in harmful situations that vary from clients violating those terms and conditions, to sexual assaults and rape cases, to robbery. For instance, some clients impose their terms on workers because of their political rank.

There is a tension between religious guilt and sex workers' rights. Although some sex workers recognise themselves as workers, they believe that they are sinful because of what they do. Some of them argue that maybe if they had not been socialised with religion as a major cornerstone in hegemonic cultures, they would not have been experiencing guilt. However, they believe that they should neither be tortured, nor exposed to sexual violence, and that they should be given their social services and tried freely and fairly.

State discrimination uses religious shame to impede sex workers' rights; its discrimination towards sex workers acts as a blockade in achieving their labour rights and increases their stigma by capitalising on religious shame. In several incidents, the state security apparatus misused their power by extorting sex from sex workers. They view sex workers' bodies as unrapeable bodies that should be controlled and disciplined. They employ methods of coercion such as insults and torture to show sex workers that they are sinful criminals. Generally, the state's attitude towards women consists in in blaming them when they get harassed, or penalising them when they carry condoms and so forth. Moreover, the discriminatory laws in place make it even harder on the lives of sex workers. The fact that the Egyptian penal code regards male clients as witnesses, not criminals, demonstrates to what extent gender discrimination is rooted and reflected in the state policies. 
Kohl 2.2

\section{References}

Bernstein, E. (2007) Temporarily Yours: Intimacy, Authenticity, and the Commerce of Sex. Chicago: University of Chicago Press.

Biancani, F. (2012) Sex Work in Colonial Cairo, 1882-1952. London: London School of Economics and Political Science.

Brooks-Gordon, B. (2008) "State Violence Towards Sex Workers," British Medical Journal 337 (7669) pp.527-528.

Farley, M. (1994) "Prostitution: The Oldest Use and Abuse of Women," Off Our Backs, inc. 24 (5) pp.14-15, 22.

Gangoli, G. (1998) "Prostitution, Legalisation and Decriminalisation: Recent Debates," Economic and Political Weekly 33 (10) pp.504-505.

Ghosh, S. (2006) "Empowerment of Sex Wokers: The Kolkata Experience," Economic and Political Weekly 41 (13) pp.1289-1291.

Gilfoyle, T. J. (1999) "Prostitutes in History: From Parables of Pornography to Metaphors of Modernity," The American Historical Review 104 (1) pp.117-141.

Global AIDS Response Progress Report (2012) National AIDS Program Egypt (Cairo: NAP).

Grant, M. G. (2014, March 5) "Let's Call Sex Work What It Is: Work," The Nation. (Online). Available at: http://www.thenation.com/article/178683/lets-call-sex-work-what-it-work (Accessed: 3rd May 2014).

Guest, G., Bunce, A. and Johnson, L. (2006) "How Many Interviews Are Enough?: An Experiment with Data saturation and Variability," Field Methods 18 (1) pp.59-82

Holder, Z., Goodson, T., and Farley M. (1994) "Prostitution Debate Continues...," Off Our Backs, inc. 24 (8) pp.24-25, 28.

Jenness, V. (1990) "From Sex as Sin to Sex as Work: COYOTE and the Reorganization of Prostitution as a Social Problem," Society for the Study of Social Problems 37 (3) pp.403-420.

Kabbash, I.A., Abdul-Rahman, I., Shehata, Y.A., and Omar, A.A-R. (2012) "HIV Infection and Related Risk Behaviours among Female Sex Workers in Greater Cairo, Egypt," Eastern Mediterranean Health Journal 8 (9) pp.920-927.

Liberto, H. R. (2009) "Normalizing Prostitution versus Normalizing the Alienability of Sexual Rights: A Response to Scott A. Andreson," Ethics 120 (1) pp.138-145.

Mahdavi, P. (2010) "Race, space, place: notes on the racialisation and spatialisation of commercial sex work in Dubai, UAE," Culture, Health \& Sexuality 12 (8) pp.943-954.

McClintock, A. (1992) "Screwing the System: Sexwork, Race and the Law," Feminism and Postmodernism 19 (2) pp.70-95.

Move Forward (2010) STI-Aids Netherlands (Netherlands: SOAIDS).

Nag, M. (2003) "Preventing AIDS among Sex Workers," Economic and Political Weekly 38 (40) pp.42094210.

---. (2005) 'Sex Workers in Sonagachi: Pioneer of a Revolution', Economic and Political Weekly 40 (49) pp.5151-5156.

Oakley, A. (1982; 1990) "Interviewing Women: A contradiction in terms," Roberts, H. (eds.) Doing Feminist Research (Routledge \& Kegan Paul plc) pp.30-62. 
Pateman, C. (1999) "What's wrong with Prostitution?," Women's Studies Quarterly 27 (1/2) pp.53-64.

Pollitt, K. (2014, April 2) "Why Do So Many Leftists Want Sex Work to Be the New Normal?," The Nation. (Online). Available at: http://www.thenation.com/article/179147/why-do-so-many-leftists-want-sexwork-be-new-normal\# (Accessed: 3rd May 2014).

Robinson, C. (2011) Real World Research (John Wiley \& Sons).

Sultana, H. (2015) "Sex worker activism, feminist discourse and HIV in Bangladesh," Culture, Health \& Sexuality 17 (6) pp.777-788.

Trappolin, L. (2005) "Gender Victims and Cultural Borders: The Globalization of Prostitution in Italy," Dialectical Anthropology 29 (3/4) pp.335-348.

Werth, P. W. (1994) "Through the Prison of Prostitution: State, Society and Power," Social History 19 (1) pp.1-15. 